\title{
DESENHO EM ANTROPOLOGIA: NOTAS E EXPERIMENTAÇÕES
}

Jeferson Carvalho da Silva ${ }^{1}$

UFV, Viçosa-MG, Brasil

\begin{abstract}
Neste ensaio apresentam-se breves experimentações sobre os usos de desenho em antropologia. São anotações, rabiscos e apontamentos retirados de diários de campo que retratam a construção de uma narrativa etnográfica em que os desenhos se encontram como agentes produtores de relações e se integram como parte desse processo reflexivo de descrição. Na primeira parte, encontram-se experiências dentro de um ambiente familiar, na segunda, em um ambiente ainda desconhecido. As duas dentro de cozinhas, observando os movimentos que se encontram nesses locais envolvendo pessoas e objetos, numa constante dinâmica de aspectos materiais e de significação.

Palavras chave: antropologia, desenho, etnografia, experimentação, cotidiano
\end{abstract}

\section{INTRODUÇÃO}

Pouco a pouco, páginas vazias preenchem-se com rabiscos; frases curtas apressadamente escritas; traços esguios criando formas irregulares; significados e lembranças sendo impressos no movimento de tornar concreta a memória efêmera do tempo vivido. A construção de cadernos de campo é uma constante dos trabalhos antropológicos. Assim, esses possuem suas singularidades e carregam em si o grande potencial de revelar, em forma documental, o que se passa entre dois mundos, de caracterizar algo vivo e em mutação na construção do conhecimento antropológico (Taussig 2011).

Do mesmo modo que as notas escritas, os desenhos e as linhas se colocam como parte das documentações que constroem os trabalhos de antropólogos(as). Os desenhos servem como

1 Estudante de Ciências Sociais da Universidade Federal de Viçosa, Minas Gerais, Brasil. Contato: jefercarvsilva@gmail.com. 
apoio à escrita dos textos etnográficos, constituem parte de suas narrativas e são capazes de elucidar detalhes que passam despercebidos pela instantaneidade das fotografias. O poder das imagens fotográficas recai sobre sua tecnologia - a imagem é controlada pelo(a) antropólogo(a), mas é a câmera que produz a imagem. Por esse motivo, deve-se evitar certa dependência a esse meio: configurando a quebra da mecanicidade de uma imagem instantânea, o tempo de produção dos desenhos possibilita uma entrega sensorial do(a) antropólogo(a) ao momento vivido, diferente do que ocorre em sua relação com a máquina (Causey 2017).

Os esforços de incorporar os desenhos às reflexões antropológicas e suas ferramentas, segundo Karina Kuschnir (2016), derivam do gosto que antropólogos(as) possuem sobre as experiências que se encontram ao redor da prática de traçar linhas no papel. Dessa forma, os interesses para construção do presente trabalho surgiram justamente pelo gosto de produzir rabiscos. Pela tentativa da construção de um diálogo possível entre os desenhos e as práticas antropológicas.

Em vista disso, o que se segue são ensaios simples e anotações retiradas de diários de campo, bem como registros de movimentos reflexivos e autobiográficos. O primeiro ocorreu em um ambiente familiar e conhecido, a cozinha da casa de minha avó. Assim, o objetivo era colocar em questão abordagens de estranhamento e distanciamento. Já o segundo ocorreu em um ambiente desconhecido e não familiar, a cozinha do principal edifício administrativo da universidade. Ambos em cozinhas, vale destacar, motivados pelo caráter instigante desses locais em constante transformação.

Para além do ato de comer e preparar alimentos, em um complexo arranjo de relações entre pessoas e objetos, a materialidade espacial das cozinhas se molda reconfigurando-se inúmeras vezes ao longo de um mesmo dia. Desse modo, a dinâmica e constância das atividades exercidas nesses locais revelam seus diversos usos e ressignificações, já que as duas cozinhas observadas são capazes de nos revelar múltiplos ambientes que se constroem em um mesmo espaço.

\section{DO COMEÇO NA COZINHA CONHECIDA}

A voz calma, os passos lentos, o cheiro de café preenchendo cada canto da cozinha, a mesa, o pano de prato pendurado na alça do forno do fogão, o vapor da água esquentando, a luz entrando pela pequena janela de vidro, os bancos, os copos azuis de plástico. $\mathrm{O}$ ambiente me é familiar. No entanto, meu olhar corre pelo espaço como se os objetos ali presentes nunca me tivessem sido apresentados, como se os gestos e as palavras, tão simples em um primeiro momento, me fossem mostrados pela primeira vez. Seguro o biscoito de polvilho em uma das mãos e provo devagar, como se não soubesse o seu sabor.

De início, ela não percebe o lápis correndo rápido pela folha de papel, e, presa em seus afazeres, desata a soltar confissões cotidianas. Fala sobre como está o tempo e diz coisas sobre o uso do micro-ondas. Escuto sobre as poucas vezes que esse forno é utilizado (nas raras ocasiões em que se estoura pipoca ou esquenta algo para comer), e também sobre o medo de utilizar o aparelho. Medo adquirido pelas tantas histórias que dizem sobre como a agitação das partículas dentro da caixa branca de metal podem fazer mal. Agora, na maior parte dos dias, ele fica esquecido em seu canto, inutilizado de suas funções e atribuído a permanecer na cozinha servindo de lugar para sacos de pão e, vez ou outra, potes e vasilhas vazios. (Diário de Campo, 17 de dezembro de 2016, às 15h05, Alto Rio Doce, Minas Gerais.) 
Ela, a quem me refiro, é Maria da Conceição, de 76 anos, minha avó e dona da cozinha em que busquei realizar uma de minhas primeiras tentativas de distanciamento e experimentação do desenho como uma forma de reflexão e envolvimento antropológico.

Figura 1. Registros da hora do café, Dona Maria e os objetos da cozinha.
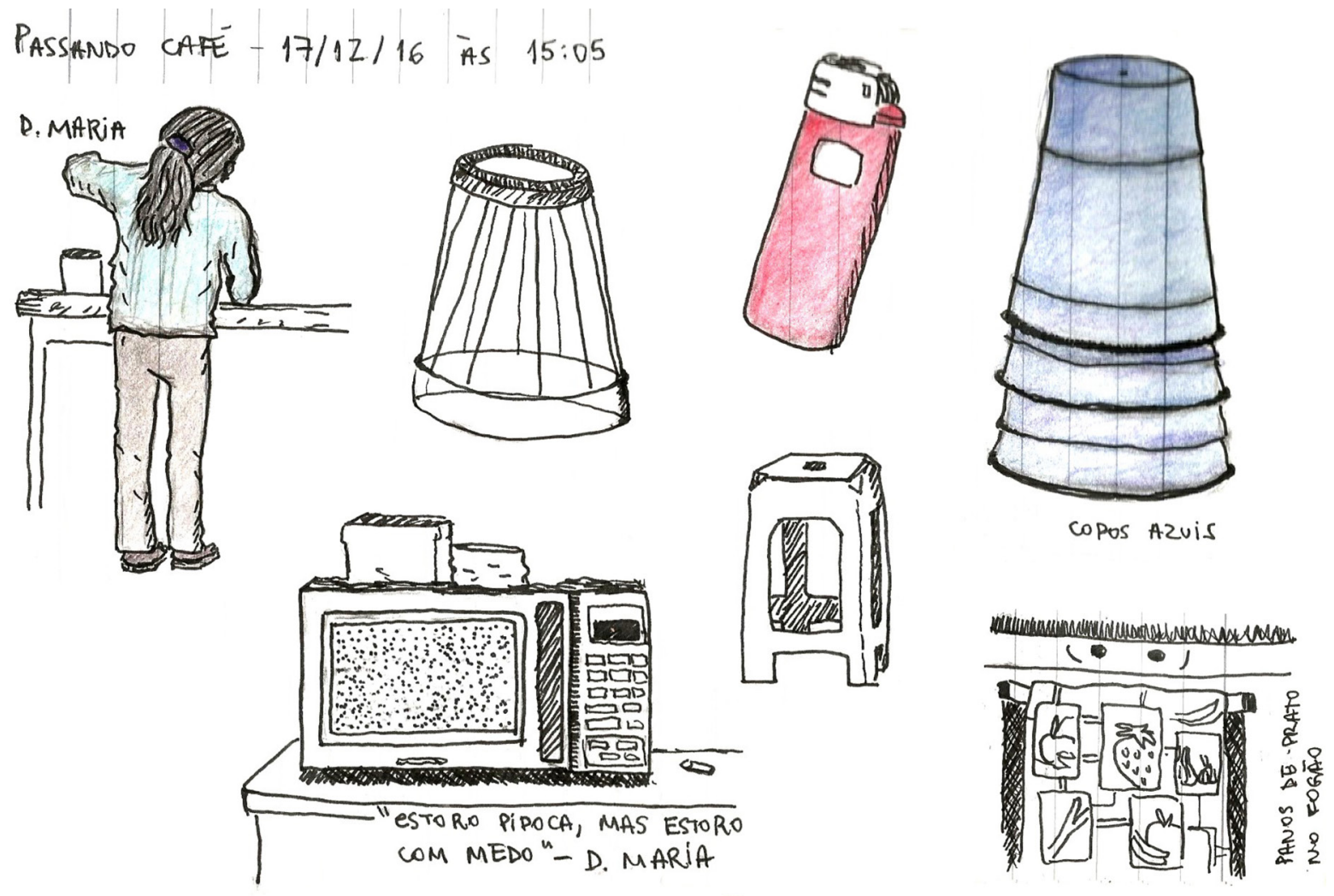

Quando decidi me aventurar em uma jornada de experimentação, unindo traços e rabiscos no papel a pensamentos e questões às quais estava sendo apresentado, embarquei em uma espécie de aventura prática e visual das palavras de Gilberto Velho (2003) acerca do que nos é familiar. $\mathrm{O}$ autor mostra como se torna necessário, por vezes, olhar de outras maneiras - e até com certo estranhamento - para aquilo que se apresenta como conhecido e próximo a nós, abrindo caminhos por onde possam surgir novas informações e perspectivas, numa tentativa de distanciamento de si para que, então, aconteça uma aproximação com o outro.

No momento em que estava desenhando, não me encontrava preso nas concepções estéticas dos traços, mas sim nos vínculos que estava estabelecendo em relação ao lugar onde me encontrava e às palavras que me estavam sendo ditas. Buscando a rememoração posterior do momento que se passava, comecei a recorrer aos registros materiais dos objetos presentes no ambiente, observando as interações de minha avó com os mesmos e a maneira como eles preenchiam o entorno ganhando novas e distintas significações, ao mesmo tempo que banais e corriqueiras.

Seus movimentos ritmados seguindo um impulso calcado pela prática constante. $\mathrm{O}$ riscar do isqueiro sem gás para acender uma das bocas do fogão, o fogo azul que aquece o caneco marcado pelo tempo, o abrir dos potes preenchidos por açúcar e café, as colheres e medidores para despejá-los na água fumegante, o cuidado de fazer com que o líquido escorra pelo filtro sem que transborde, a delicadeza dos movimentos ao misturar tudo enquanto a bebida escorre para dentro da garrafa térmica. (Diário de Campo) 
Segundo Gomes (2016), os desenhos constroem-se orientados a partir das formas como seu(sua) autor(a) vê o mundo, e, dessa forma, compreendi aquele momento. Se antes meus desenhos preenchiam as folhas em branco de maneira despretensiosa, agora eles guiavam meu olhar pelo ambiente ancorados nas bagagens recém adquiridas nas disciplinas do curso de Ciências Sociais.

Enquanto vozes vindas da cozinha quebram o silêncio, sento-me ao seu lado com o caderno em mãos. A pouca luz cobrindo os antigos móveis; no quarto, a cama de casal, o guarda-roupa, a cômoda, com perfumes e santos, a parede com um pequeno quadro do dia do casamento, e a imagem emoldurada de Nossa Senhora de Fátima.

Cuidadosamente ela coloca um rádio antigo em cima do banco encostado na parede e aperta alguns botões. A voz do padre proferindo a missa das sete horas abafa os murmúrios do outro cômodo e embala o ambiente por escurecer. Minha avó, como que esquecida de tudo, ou ainda com as lembranças mais vivas do que nunca, encara o aparelho como se ali em frente pudesse encontrar o dono das falas ruidosas.

O lápis percorre em silêncio o branco do papel, gravando mais em mim as nuances do momento do que na folha do caderno em si. O estímulo de buscar e registrar o que estava acontecendo talvez fosse o mais marcante no momento de riscar o papel, e o que mais me diria depois sobre o que estava se passando. (Diário de Campo, 17 de dezembro de 2016, às 19h36, Alto Rio Doce, Minas Gerais.)

Figura 2. Rabiscos sobre a missa no rádio.
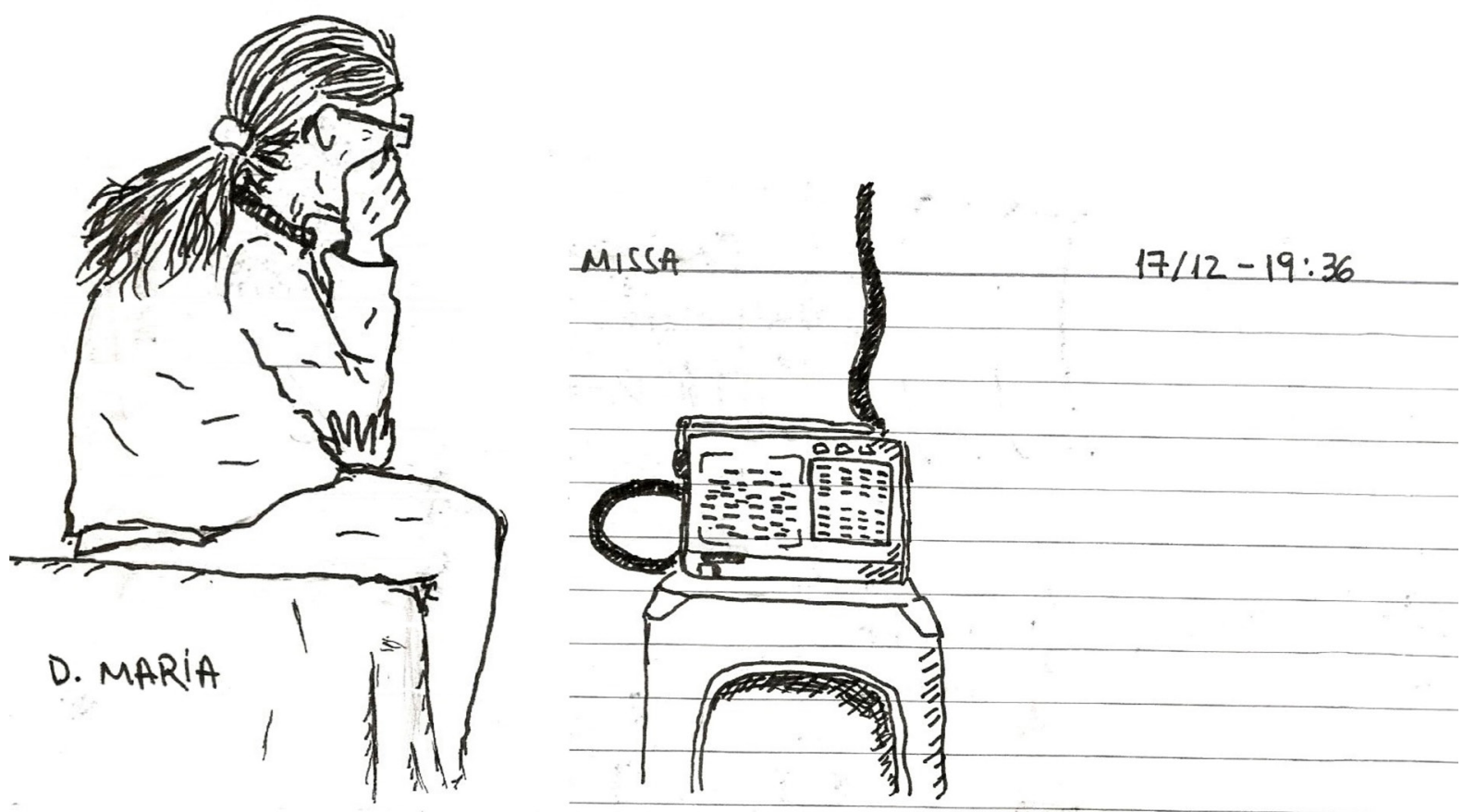

Para além das observações dentro da cozinha, é interessante perceber como outros espaços podem ser ressignificados. A missa no rádio acompanhada logo em seguida pela missa na igreja da cidade nos revela como outros espaços domésticos (o quarto, nesse caso) podem assumir outras espacialidades e distribuições de significados, seja pela a interação das pessoas ou pela agência de objetos (como o rádio, por exemplo). 
Figura 3. Missa de domingo. 18 de dezembro de 2016, às 07h21, Alto Rio Doce, Minas Gerais.

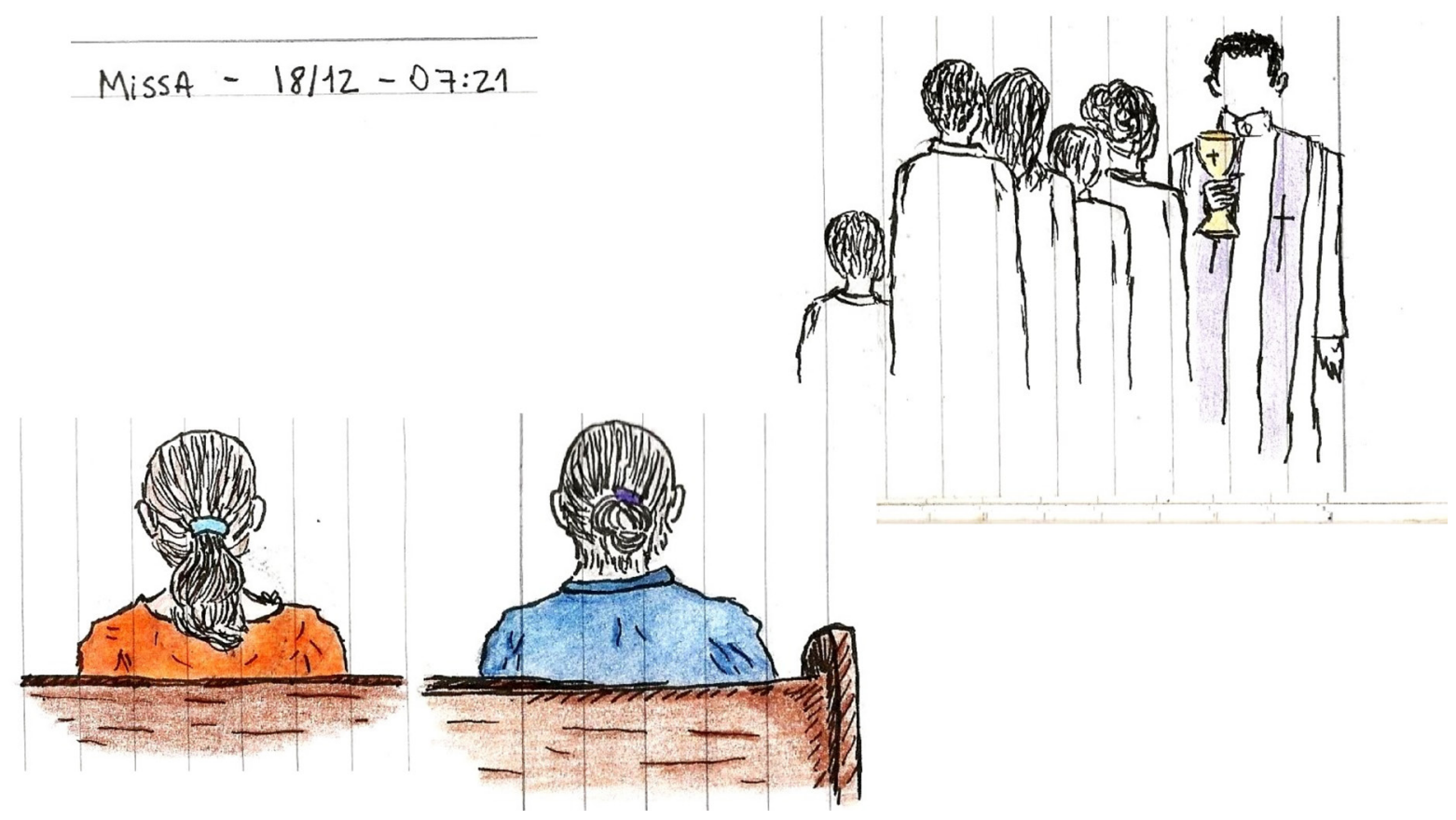

Figura 4. Notas sobre a primeira conversa com Nanica, pela manhã. Maria Aparecida, antiga amiga de Dona Maria que a visita praticamente todas as manhãs, para conversar e trazer "agrados". 19 de dezembro de 2016, Alto Rio Doce, Minas Gerais.
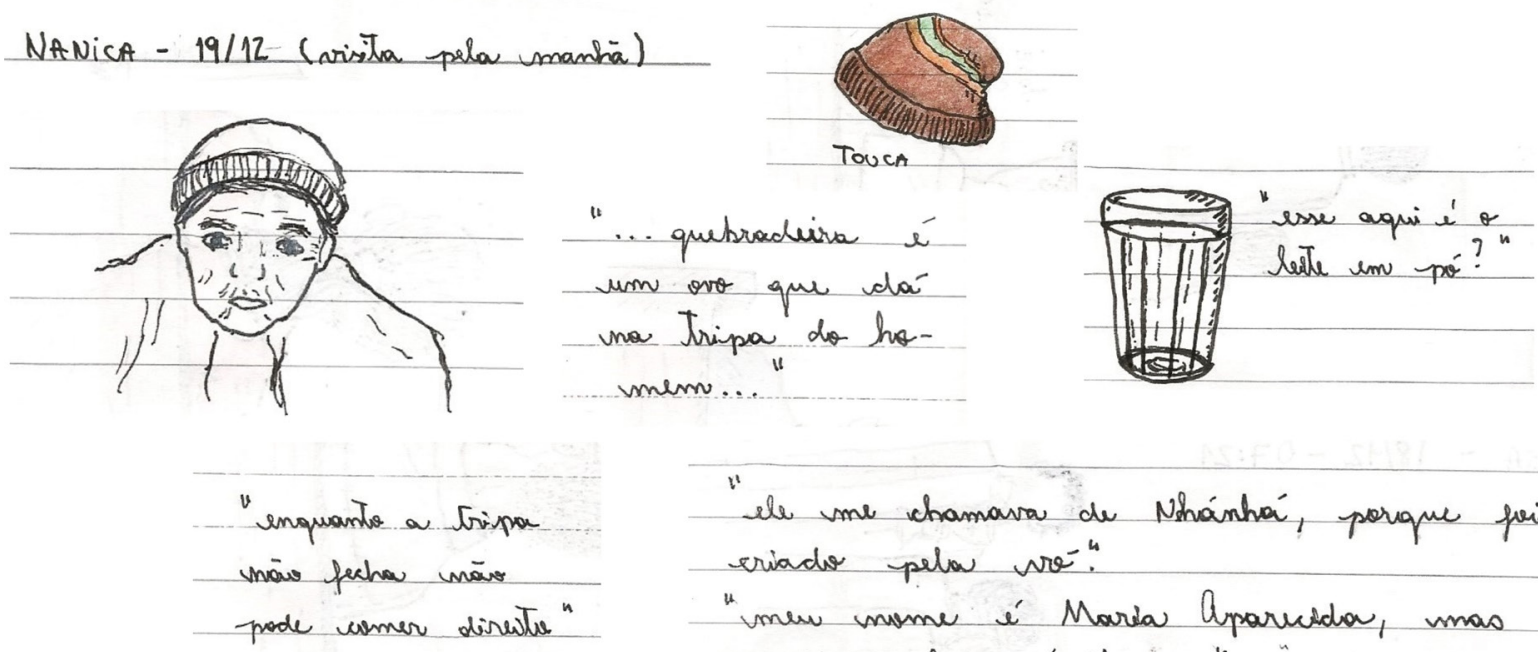

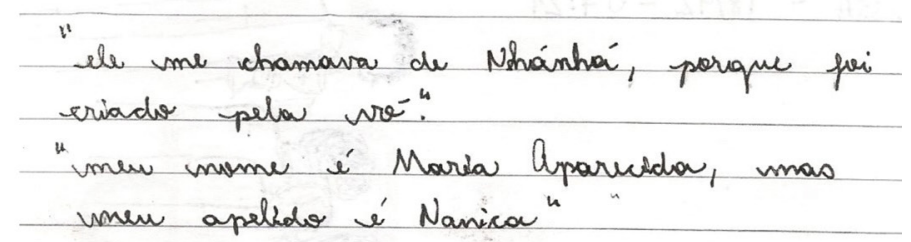


Figura 5. Rabiscos da hora do almoço; Dona Maria cozinhando e os objetos da cozinha. 22 de dezembro de 2016, às 09h47, Alto Rio Doce, Minas Gerais.
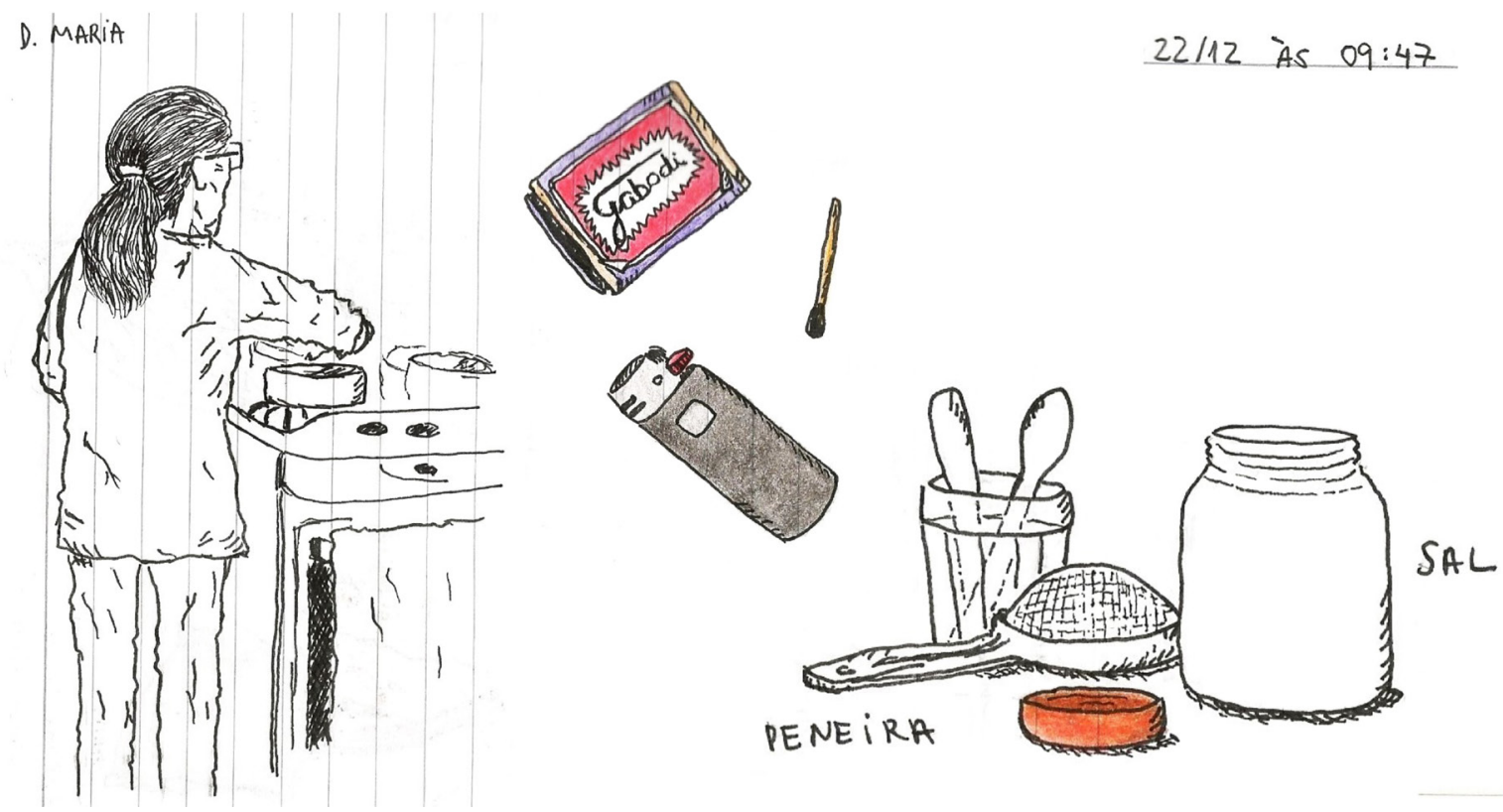

Figura 6. Visita de Nanica durante o preparo do almoço, notas; fuga e entrega de "agrado". 22 de dezembro de 2016, às 10h02, Alto Rio Doce, Minas Gerais.

NANICA - 22/12-10:02

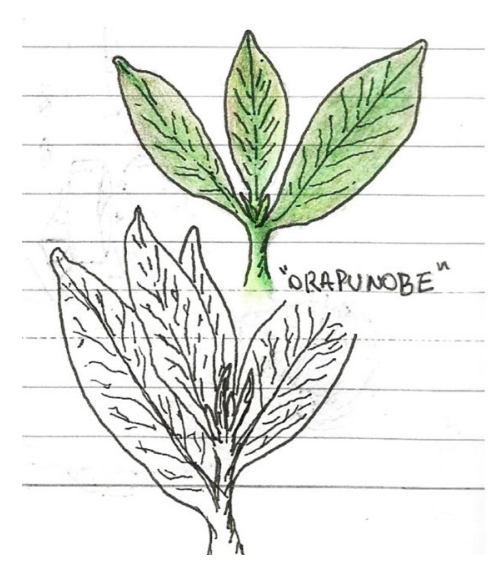

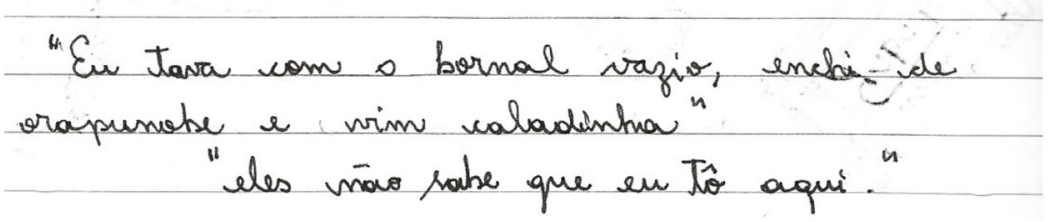

"Jiló uñó como, amarga minha hoca" "leite tambím tá amargando minhor bocar Tombeim "

\section{DAS TENTATIVAS NAS COZINHAS DESCONHECIDAS}

A falta de jeito. Desenhar com tantos olhares parecia ser um desafio, ainda mais por saberem o motivo pelo qual eu estava ali com um bloco de folhas, algumas canetas, lápis e olhares para coisas corriqueiras do cotidiano das pessoas que ocupavam aquele local. $\mathrm{O}$ primeiro contato foi sem grandes problemas: Fui acolhido com muita receptividade, mesmo que os meus propósitos e intenções (por terem sido mal explicados?) não tivessem sido interpretados da maneira como estava esperando. 
Quando anunciei que iria passar um tempo desenhando e perguntando algumas coisas nos intervalos de folga durante o expediente deles, logo criaram expectativas sobre a minha presença. Achavam que eu estava ali para desenhar o ambiente, e só isso: "Acho que ele vai desenhar essa geladeira, essa trava que eu sempre deixo aberta, as meninas sempre reclamam, coitadas." - diz uma moça que trabalha na sala ao lado e que também utiliza o espaço. Envergonhado e um pouco sem jeito, não vejo outra saída e acabo por desenhar a geladeira, enquanto ela e outra das mulheres que estavam ali fazem brincadeiras entre si, cogitando quem ou o que poderia ser desenhado.

Figura 7. Geladeira, vassoura e objetos espalhados sobre a mesa.
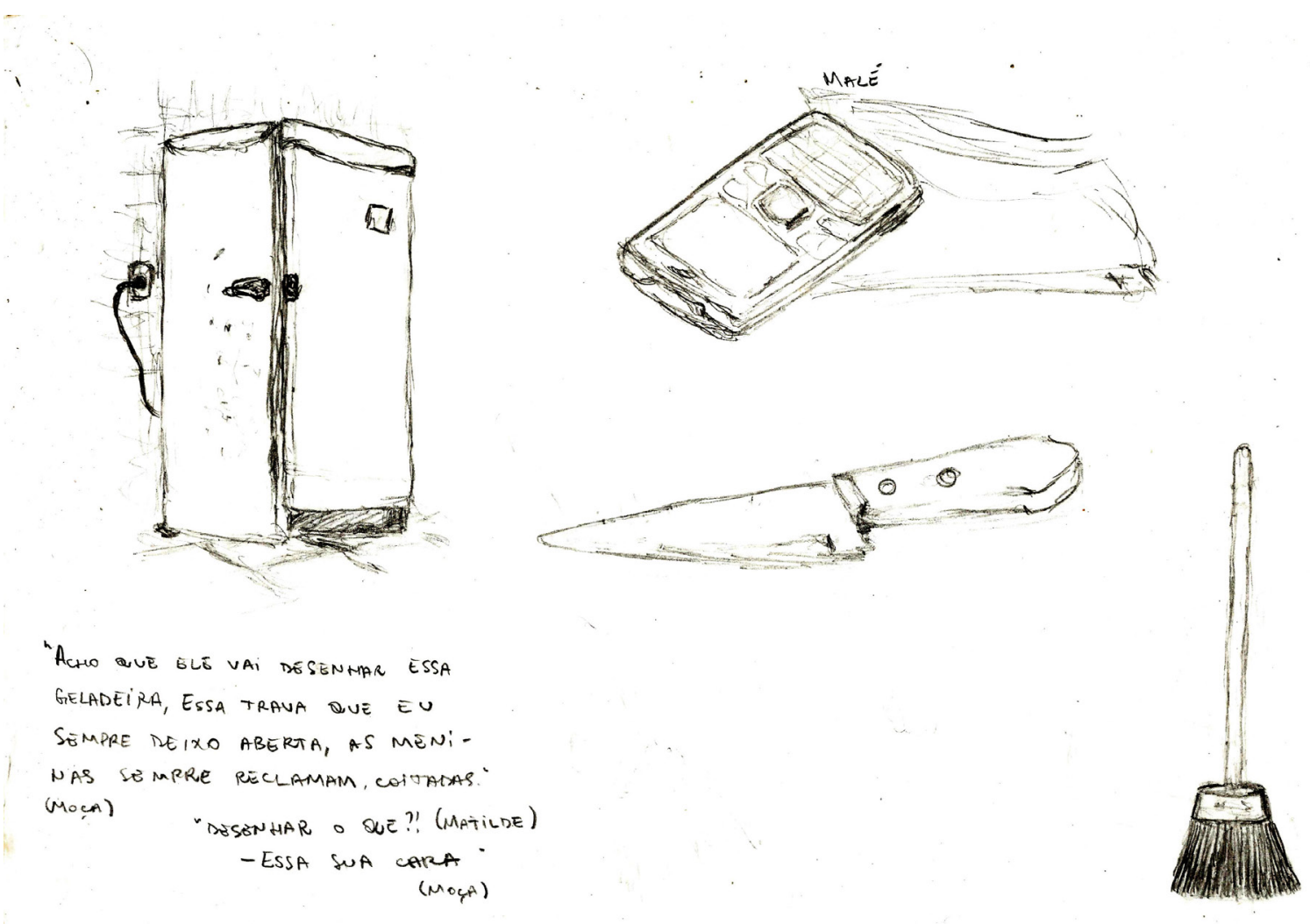

$24 / 04 / 17-15,00$

Mais uma vez eu estava dentro de uma cozinha, essa agora não mais conhecida e familiar, e sim um ambiente desconhecido com pessoas que eu não havia tido contato até então. Contavam-se sete pessoas a transitar e ocupar aquele espaço, trocando diariamente, nas poucas horas de folga, relatos pessoais sobre família, incertezas e as vivências do cotidiano de trabalho, deixando espalhados objetos particulares e aproveitando os momentos de intervalo entre as tarefas rotineiras.

Embora me sentisse muito acolhido e confortável ao lado das pessoas que estavam ao redor, o ambiente em si não me abrigava de fato, era como se fosse projetado para outros e estar ali quebrava totalmente com o desenho inicialmente planejado. Sendo assim, me sentia um intruso.

Contudo, consegui perceber que estar dentro da cozinha auxiliado de folhas e canetas, criando traços e estabelecendo vínculos com as pessoas que a ocupavam, garantiu minha presença ali, e serviu como um disparador de conversas, além de criar certa situação de conforto e confiança diante da minha falta de jeito inicial. Pontes de interesse puderam ser criadas: de minha parte por ter a possibilidade e garantia de compartilhar daqueles momentos particulares com eles(as) e por parte deles(as) por desejarem ver os desenhos prontos depois. (24 de abril de 2017, às 15h00, Viçosa, Minas Gerais).

Cheguei em frente à porta. Vozes animadas conversavam do outro lado, bati. Silêncio. Depois de alguns segundos a porta é aberta. Os ocupantes sorriem aliviados ao se depararem com minha figura e não com a imagem do "chefe". Matilde, ressabiada em seu canto, ao lado da geladeira, murmura sobre nem se preocupar 
mais com quem bate à porta.

A manhã foi passando rápido. Antes de todos saírem para dar início às suas rotinas de trabalho, conversamos sobre as plantas que estavam na janela. "As plantas quem plantou foi a outra, Ivonete" - Matilde. "Essa aqui é hortelã... babosa... os outros não são chá.” - Mazé. E ouvi sobre Mazé ter que ir encontrar com seu chefe para resolver o problema de sua digital para "bater o ponto" ("Quem tá na garupa não governa as rédeas" Jackson). Ela contou sobre ser alérgica às luvas, e sobre quando tinha que lavá-las por conta do "pózinho" que tinha nelas. Nem mesmo luvas antialérgicas têm adiantado muito, ainda assim é obrigada a usá-las: "Se a gente não usar luva leva advertência, né” - Mazé. (Diário de Campo, 26 de abril de 2017, Viçosa, Minas Gerais).

Do pequeno período que estive em contato com as pessoas que ocupavam a cozinha do principal edifício administrativo da universidade, o pouco que pude criar de vínculo e relações com as pessoas daquele ambiente me revelaram outras formas de se experimentar o cotidiano dentro do congestionado ambiente acadêmico. Pude perceber, portanto, reflexos das dinâmicas de poder dentro das estruturas do local, além de conseguir refletir sobre minhas próprias posturas ao me colocar em um ambiente totalmente novo e com pessoas, até então, desconhecidas.

\section{DAS COZINHAS E DOS DESENHOS ETNOGRÁFICOS}

Seja nas sugestões do que eu deveria ou não desenhar ou no resgate de memórias, os desenhos se mostraram como elementos capazes de implicar em uma rede de relações em que eles próprios e os objetos retratados se tornavam agentes inventivos das interações vividas com as pessoas. Num movimento de imersão e quebra da constante cotidiana experimentada por essas pessoas, minha presença e produção provocou certa agentividade e reflexão sobre suas práticas, acionando posturas de alteridade.

A observação da composição material e dos movimentos nas duas cozinhas revela uma reconfiguração constante desses espaços, suscitada pelas relações de seus ocupantes e pelo trânsito de objetos que ora entram e saem de dentro de gavetas e armários, ora espalham-se por mesas e balcões. Panelas que são utilizadas na hora do almoço escondem-se na hora do café, dando espaço a copos e canecos que antes não se encontravam ali. Embora as duas cozinhas observadas possuam distanciamentos, geográficos, e no que diz respeito aos seus usos, ambas apresentam aproximações que podem nos dizer sobre os fluxos e trocas que se desenrolam em seu interior e são capazes de reconfigurar seus arranjos e espacialidades.

Alguns dos objetos observados em ambas as cozinhas se colocam como agentes e mediadores de relações, tanto entre pessoas como entre as pessoas e o espaço. Um exemplo é a trava da geladeira, que suscita pequenos conflitos entre os(as) ocupantes da cozinha compartilhada do edifício administrativo da universidade, outro é o microondas da cozinha de minha avó que teve seus usos ressignificados em relação ao espaço devido às histórias contadas sobre o aparelho.

A produção de desenhos implica aos(às) antropólogos(as) uma série de escolhas e decisões sobre quais os traços, contornos e formas vão ser utilizados para representar com honestidade o que está sendo observado (Causey 2017). Assim sendo, todo o processo de construção dos desenhos se baseia em movimentos de reflexividade e escolhas a serem feitas e se encontram submetidos a um compromisso com aqueles(as) que estão sendo retratados ou que guiam as maneiras como se retrata o entorno. 
Desse modo, desenhar em um ambiente conhecido foi um ato de ressignificação, de ser guiado através do desenho por pessoas e objetos familiares. Já realizar tal experiência em um local desconhecido se mostrou como um desafio, portanto, minha observação se tornou cautelosa e as indicações sobre como realizar os desenhos se davam em nuances de palavras e movimentos soltos.

Como afirma Gomes (2016: 86): "Desenhar é como conversar. É como estar num diálogo constante com o espaço, com as formas, as perspectivas, mas é também estar e conversar com as pessoas". Logo, os desenhos, para além da tentativa de transmissão das cores, texturas, cheiros, nuances, sobreposições e dinâmicas vividas e observadas, podem criar experiências de reconhecimento mútuo e dialógico entre antropólogos(as) e as pessoas envolvidas em campo, guiados(as) por outro olhar e suas próprias percepções sobre aquilo que é retratado.

\section{BIBLIOGRAFIA}

Causey, Andrew. 2017. Drawn to see: drawing as an ethnographic method. Toronto: University of Toronto Press.

Gomes, Inês Belo. 2016. “Deixei o desenho enterrado’ ou como ressuscitar o grafismo enquanto metodologia antropológica: um caso prático”. Cadernos de Arte e Antropologia, Vol. 5, No $2 \mid-1,75-90$.

Kuschnir, Karina. 2016. "A antropologia pelo desenho: experiências visuais e etnográficas". Cadernos de Arte e Antropologia, Vol. 5, No 2 |-1, 5-13.

Taussig, Michael. 2011. I Swear I Saw This: Drawings in the Fieldwork Notebooks, Namely my Own. Chicago: University of Chicago Press.

Velho, Gilberto. 2003. "O desafio da proximidade”. pp. 11-19. In: Velho, Gilberto; Kuschnir, Karina (orgs.). Pesquisas urbanas: desafios do trabalho antropológico. Rio de Janeiro: Jorge Zahar Editor.

\section{DRAWING IN ANTHROPOLOGY: NOTES AND EXPERIMENTS}

This essay presents some experiments on the uses of drawing in anthropology, composed of notes, scrib-
bles and details taken from field notebooks that depict the construction of an ethnographic narrative, in
which drawings work as agents of relations, being integrated within a reflective process of description.
The first part presents drawing experiences within a familiar environment, the second part, within a
yet unknown environment. Both of them belong to kitchens, and observe the movements that are going
on in these places, involving people and objects in a constant dynamic of materiality and signification. Keywords: anthropology, drawing, ethnography, experimentation 